Boston University School of Law

Scholarly Commons at Boston University School of Law

Faculty Scholarship

2018

Saving Face: Unfolding the Screen of Chinese Privacy Law

Tiffany Li

Jill Bronfman

Zhou Zhou

Follow this and additional works at: https://scholarship.law.bu.edu/faculty_scholarship

Part of the Privacy Law Commons 


\title{
SAVING FACE: UNFOLDING THE SCREEN OF CHINESE PRIVACY LAW
}

\author{
Tiffany Li, Zhou Zhou, Jill Bronfman ${ }^{*}$
}

\section{INTRODUCTION}

Traditional Peking Opera is one of the most well-known and characteristic art forms of historical and modern-day China- one that is as emblematic of Chinese culture as baseball is of the United States. During each performance, Beijing Opera actors cycle through a variety of dramatically painted masks, with each mask using color and style of face to elaborately symbolize particular traits. Experienced opera-goers are expected to recognize that a yellow or white face is a "malicious character," and the degree or amount of makeup applied represents the degree of each character's malevolence. With the faces of the actors covered, the operas become a performance of inner thoughts and emotions expressed behind a very literal mask.

While it may be overly simplistic to sum up six thousand years of Chinese history in one metaphor, the sustaining influence of Beijing Opera is a metaphor to allow Western audiences to easily understand the cultural value of "face." The concept of face in Chinese culture (and other Asian cultures) refers to a complex cultural valuation of protecting personal privacy in order to present a respectable identity to the community at large. In traditional Beijing Opera, actors use masks to shield their identities on stage, and the masks allow the actors to present carefully calculated "faces" to the public. Similarly, Chinese privacy laws can be understood through the lens of "saving face" as these laws protect Chinese citizens from having their

* The Authors would like to express our appreciation for the advice and support of the International Association of Privacy Professionals (IAPP), IP Scholars Asia, the Privacy Law Scholars' Conference (PLSC), the Asian Privacy Law Scholars' Network (APSN), The University of Washington School of Law, The University of Geneva, and the University of California Hastings College of the Law.

${ }^{1}$ Fayuan, Zhu, Qixing, Wu, Hanning, Xia, and Han, Gao, From Moon Cakes to Mao to Modern China: An Introduction to Chinese Civilization, (2015) by CN Times Books, Inc., p. 206.

${ }^{2}$ There is a literal meaning of face as well as a figurative meaning of face in the Chinese language, "Besides its original meaning, this term [face] is a literal translation of the Chinese 'mian-zi' and 'lian'." "Mian-zi" is reputation such as success and ostentation, whereas "lian" is moral character or standing in the community. To lose face is to fail to achieve the community's approval, to be dishonored, to be humiliated in public. Wang, Hao, Protecting Privacy in China, A Research on China's Privacy. Standards and the Possibility of 
personal information exposed, thus allowing individuals to present their identity (or personal information) to the community in ways that they choose.

This Article seeks to elucidate the connection between Chinese cultural values and China's privacy laws, with the ultimate goal of offering predictions and recommendations for future Chinese privacy law and policy. This research comes at a crucial time in history. Changes in economic systems and technology, along with the forces of the Internet, Western entertainment and education, have transformed and uprooted Chinese life. Urbanization has increased the disconnection of the individual from the family and collective units of the past. Economic changes favor the individual and individual rights in the private sphere, but in the public sphere, the government still plays a large role.

While analyzing the cultural foundations of Chinese privacy law is an intellectually interesting exercise, it is also one that is critical to the future economic interests of the world. Considering its economic influence and immense consumer base, any international company seeking to operate in China should expend resources on understanding how best to succeed in the Chinese market, taking into account the current privacy landscape. In addition, technical developments in information transmission, including Internet, mobile apps, cloud storage, and data analytics, require a global perspective on data protection.

China has moved forward in a nimble fashion to take advantage of advances in technology. For example, "China has emerged as a leader in genomic research...the Beijing Genomic Institute (since renamed BGI) is now the largest genomic research center in the world, with more sequencing machines than the entire United States. Some of its researchers are in early discussions about eventually sequencing the genomes of almost every child in China." ${ }^{3}$ The privacy and data protection obligations of such a database are potentially enormous. This means that privacy scholars and practitioners everywhere must pay close attention to how privacy law is developing in China, both to keep up with current developments and to stay ahead of the curve by proactively implementing strategic privacy and data security policies.

This article will address some of those unique historical and cultural

Establishing the Right to Privacy and the Information Privacy Protection Legislation in Modern China, Springer-Verlag Berlin Heidelberg, 2011, p.38-39. As another commentator noted, "social face ["mian-zi"], [is] based on one's achievements and dignity, and moral face ["lian"], based on a person's feelings of shame. The former works as a type of prestige and is subject to the evaluation of others, while the latter functions as a moral self-constraint." Yan, Yunxiang, Making Room for Intimacy, House Home Family: Living and Being Chinese, ed. By Knapp, Ronald G. and Lo, Kai-Yin (2005) Spatial Habitus, p. 395, fn. 4.

${ }^{3}$ Ross, Alec, The Industries of the Future, Simon \& Schuster (2016), p. 65. 
factors that might provide clues to the future of the development and application of privacy laws in China. First, we look at cultural factors that may influence the unique Chinese conception of privacy. Second, we analyze current relevant Chinese privacy laws and regulations. Finally, we look to the future and offer some practical recommendations for the future of Chinese privacy law.

\section{Cultural Factors Influencing the Perception of Privacy}

As is the case for legal systems in all countries, Chinese culture affects Chinese views and application of laws - including privacy laws. However, we cannot study Chinese privacy law in a vacuum. The modern legal conception of privacy, and its applicable laws, arose from Western culture. Thus, to understand Chinese privacy law, we must juxtapose Western notions of privacy against thousands of years of Confucian teaching and the historical background of communism that still influences present-day Chinese society. ${ }^{4}$ In fact, such cultural considerations have such a strong influence on Chinese privacy laws precisely because the importation of Western privacy laws prevented China from developing its own sui generis privacy legal culture.

\section{A. Western culture based on individual values and individual privacy}

The concept of privacy in the Western tradition is said to arise out of an 1890 article by Samuel Warren and Louis Brandeis titled "The Right to Privacy." In it, Warren and Brandeis described a right to privacy as the right of an individual to be left alone. The authors frame the right as a continuation of common law traditions protecting rights of the individual, their rights in their home 'castle', and their innate rights to be left to themselves. Thus, the idea of privacy as we know it today is a relatively recent phenomenon that was developed out of a Western moral and legal framework that presupposes the primacy of individual rights against collective values, except in the most extreme circumstances.

\section{B. Chinese cultural values and history produce community-oriented privacy systems}

\footnotetext{
${ }^{4}$ For further discussion on Chinese privacy law, and Asian privacy law in general, see, Asian Data Privacy Laws: Trade and Human Rights Perspectives, by University of New South Wales Law Professor Graham Greenleaf.

${ }^{5}$ Samuel D. Warren \& Louis D. Brandeis, The Right to Privacy, 4 HARV. L REV. 193 (1890).
} 
It is, of course, impossible to definitively state which cultural and historical factors have created the current Chinese perception of privacy. Here, we look at a selection of issues that may be most relevant to today's Chinese privacy norms. With the goal of understanding Chinese conceptions of privacy, as viewed from the lens of traditional Western scholarship, we will pay particular attention to cultural and historical factors that are unique to China or that diverge significantly from traditional Western factors.

\section{Confucian System of Values}

Historically, Chinese laws arose out of Confucian ideas ${ }^{6}$ about government and have always been underpinned by Confucian ethics and morality about daily civil conduct, known as $L i$ in Chinese. These Confucian ideas are a product of a time in Chinese history, the Spring and Autumn and the Warring States periods, ${ }^{7}$ when the country was undergoing an extended and tumultuous civil war. During that turbulent time, prominent scholars like Confucius sought ways to end the turmoil. This turmoil was only ended, by the unification of China under the first emperor of China, Qin Shi Shuang. Thus, under Confucianism, and the Chinese legal systems based on it, priority is placed on ensuring order and good governance. In such a system, the rights of the individual are subordinate to the rights of the family unit, the community, and the country. As a result, "The protection of privacy (yin-si) was first stated by the famous Analects of Confucius in the early days of the Warring States periods...[however] It should be noted that the main aims of these [Confucian] doctrines and provisions were not to protect individual's personal privacy. The protection of privacy (yin-si) was only the by-product of implementing these doctrines and provisions." 8

\section{Communist Rule and Collectivism}

\footnotetext{
${ }^{6}$ Confucianism is based on a set of ethical and philosophical teachings stressing the love for humanity and family, loyalty to government, and harmony in thought and conduct with one's defined role in society. See, e.g., Judith A. Berling, "Confucianism," Focus on Asian Studies, Vol. II, No. 1: Asian Religions, 5-7 (1982).

${ }^{7}$ Spring and Autumn Period (770 - c.480 BCE) and the Warring States Period (c.480 BCE-221 BCE), "The Zhou Dynasty, Confucius, and China's Philosophic Traditions," Asia for Educators, available at $\mathrm{http} / / /$ afe.easia.columbia.edu/main_pop $/ \mathrm{kpct} / \mathrm{kp}$ zhou.htm.

${ }^{8}$ Wang, Hao, Protecting Privacy in China in A RESEARCH ON CHINA'S PRIVACY STANDARDS AND THE POSSIBILITY OF ESTABLISHING THE RIGHT TO PRIVACY AND THE INFORMATION PRIVACY PROTECTION LEGISLATION IN MODERN CHINA, 36 (2011). For a further discussion of the Chinese word for privacy, yin$s i$, see also infra p. 16.
} 
More recently in history, for many decades the Communist ${ }^{9}$ authorities strove to build a country focused on collectivism rather than individual pursuits. In an environment where private property was collectivized by the state and where communes consisting of thousands of households led to communal living, individuals rarely have control of their own tangible goods, including even a personal physical space. The idea of an individual having the right to an intangible concept like privacy, protecting them against the intrusion of the state and the community, was also relatively unheard of. Only since the modernization and opening up of the Chinese economy in the past twenty-five years ${ }^{10}$ have individuals been able to pursue their own career and life paths.

\section{Setting Privacy Boundaries Using Traditional Chinese Concepts of Deference and Respect}

Beyond the bigger picture themes, differing conceptions of individualism and community can be seen even in the small details of how greetings are made in Chinese and Western cultures. When Chinese people greet each other, it is common to comment directly on the status of the greeted individual. In Western culture, it is common to mention the weather, the time of day, or another neutral expression. In Chinese, the greetings and level of inquiry could be considered significantly more intrusive by Western standards, as they seek to ascertain the condition of the other individual, and establish the relationship between the two individuals. For example, A conversation in China often begins with the congenial and intimate, "Have you eaten?" This concern with the other individual's welfare highlights the basic assumption that no reasonable discourse can occur while someone is lacking in the essentials of life.

Differences between Chinese and Western cultures can also be found in what is considered polite avenues of inquiry in conversation with friends and acquaintances. To show consideration, and also to know exactly who one is dealing with, Chinese people are liable to ask one another questions that might seem off limits to Westerners, including, "How much money do you make?" and "How old are you?," and the ever-popular, "Are you married?" While Westerners may ask such probative questions to close friends and

${ }^{9}$ The Communist Party of China (CPC) established the People's Republic of China (PRC) in 1949.

${ }^{10}$ Chinese economic reform by Deng Xiaoping. Naughton, Barry et al. (2008), "A Political Economy of China's Economic Transition in China's Great Transformation", in Brandt, Loren; Rawski, G. Thomas, China's Great Transformation, Cambridge: Cambridge university press 
family, the key difference is that these questions would seem out of place or rude if asked of anyone without that close relationship. These questions go well beyond first encounter conversations between Westerners, and perhaps beyond first date conversations.

At first, these topics of speech may seem incredibly detailed for greetings and initial conversations, but they help Chinese individuals root and establish each other's place in the carefully constructed culture of their own design. The design of this world orients the individual and establishes boundaries that, in many cases, substitute for Western notions of privacy and individualism. The language of deference, modesty, and humility helps create a hierarchy that establishes a level of comfort and stability for each individual within that structure. Patterns of body language, official titles, and family relationship designations build on this structure.

\section{Physical Boundaries and Deference}

In historical Chinese tradition, greeting another person by bowing showed deference, and deeper bowing indicated additional levels of deference. The borrowed English word "kowtow" refers to the Chinese phrase for genuflecting in front of another as a show of humility and subservience. The modern English meaning stems from this tradition. It is worth noting that "kowtow" and "saving face" are both borrowed phrases from the Chinese language; there were literally no Western equivalents in English.

In modern times, the performative tradition of bowing to another is generally only used in formal contexts and is instead now generally reduced to a nod or other form of acknowledgment, ${ }^{11}$ However, the historical reference still exists. Bowing may still occur in formal situations with greetings between heads of state or religious leaders.

The tradition of bowing may also be reflective of Chinese norms for personal space. Personal space is significant in establishing privacy boundaries, and in a crowded, populous country, necessary. Kissing and hugging among acquaintances in traditional Chinese culture would be unusual and rare. However, actual physical space understandings in modern China are different. Modern Chinese actually have very low expectations for physical space - given the crowdedness of the cities. People are willing to stand or walk right next to strangers without leaving too much space. In contrast, sparsely populated countries like Finland are known to have great personal space expectations - a Finn would likely find that Americans stand

${ }^{11}$ Fayuan, Zhu, Qixing, Wu, Hanning, Xia, and Han, Gao, From Moon Cakes to Mao to Modern China: An Introduction to Chinese Civilization, (2015) by CN Times Books, Inc., p 14. 
much too close to strangers and make far too much eye contact. This conception of physical space also has implications for conceptions of personal physical privacy that may be different from those in the Western world. In China, what is considered polite personal space in public among strangers (very close, touching) is different from personal space between acquaintances and friends (not touching). ${ }^{12}$

\section{Official Titles}

In addition to the Western name structures of place and occupation, historically Chinese surnames had often used to include pre-Qin unification feudal titles and rank. Some people took on names of ancestors' titles of nobility and political official status. ${ }^{13}$ If the "core of propriety is using proper titles, ${ }^{14}$ then the failure to use correct titles is the failure to understand one's place in society, and thereby fail as an individual, and as a member of the family unit. This structure is attributed to Confucius, but may have roots in Chinese family structure that predated The Analects of Confucius.

\section{Family Relationship Structure}

Included in a Chinese person's name may be their actual place in their family. Part of the traditional naming convention of a Chinese given name may incorporate seniority or relationship of an elder in the family, and there were very strict rules against naming a child after a parent, ${ }^{15}$ in order to avoid the rather disastrous confusion of the young and old, as well as confusion among the lower and higher ranked individuals.

In fact, there are more than 230 words in Chinese that designate family relationship status, ${ }^{16}$ just to be absolutely clear where each individual

\footnotetext{
${ }^{12}$ Susan Krauss Whitbourne, Polish Off Your Personal Space, Psychology Today (Nov. 3, 2012), https://www.psychologytoday.com/blog/fulfillment-any-age/201211/polish-yourpersonal-space.

${ }^{13}$ Fayuan, Zhu, Qixing, Wu, Hanning, Xia, and Han, Gao, From Moon Cakes to Mao to Modern China: An Introduction to Chinese Civilization, (2015) by CN Times Books, Inc., p. 12 .

${ }^{14}$ Fayuan, Zhu, Qixing, Wu, Hanning, Xia, and Han, Gao, From Moon Cakes to Mao to Modern China: An Introduction to Chinese Civilization, (2015) by CN Times Books, Inc., p. 95.

${ }^{15}$ Fayuan, Zhu, Qixing, Wu, Hanning, Xia, and Han, Gao, From Moon Cakes to Mao to Modern China: An Introduction to Chinese Civilization, (2015) by CN Times Books, Inc., p. 13.

${ }^{16}$ Fayuan, Zhu, Qixing, Wu, Hanning, Xia, and Han, Gao, From Moon Cakes to Mao to Modern China: An Introduction to Chinese Civilization, (2015) by CN Times Books, Inc., p. 15.
} 
stands. For example, no one is just "brother," but must be called "older brother," or "younger brother," as the name suggests, and so on, beyond directly lineal relatives to in-laws, cousins, and even signifying on which side of the family (mother's or father's) the relative is placed in the family tree. In this context, "individual privacy in traditional Chinese culture existed in a hierarchical context- a person could enjoy privacy in relation to those who were ranked lower socially and economically, but not vice versa. This is because privacy was not a legal right but a flexible privilege, the boundary of which varied depending on one's social status in a situation-specific context. For instance, a landlord in a rural community could enter a poor tenant's home without any concern for the latter's privacy, but the opposite was unthinkable. This is like the operation of 'social face' in everyday [Chinese] life: an actor normally knows how 'big' the other party's face is."

Though there still is a legacy of association with secrecy, privacy in modern China has begun to incorporate private space and private concepts. One Chinese scholar noted that, "Though many common Chinese still line privacy with Yinsi (shameful secret) - to a large extent, at least in the relevant discussion of many contemporary Chinese scholars, the concept of privacy is no longer limited to the earlier, narrower sense of [Yinsi], but now includes all personal information (i.e., whether shameful or not) that people do not want others to know... This expanding scope of 'privacy' is apparently based, at least in part, on the expansion of physical personal space in China..." 18 To address this connection between privacy and community/space, we must look at the evolution of personal space, both in the literal and metaphorical sense, in context in China.

\section{Community in Chinese Culture}

Chinese communities are built upon the family and hierarchical relationships established by these linguistic and behavioral traditions. In fact, "privacy as a social practice is itself not alien to Chinese culture. On the contrary, a certain degree of privacy has always been carefully protected for some people through Chinese history. Suffice it to note that the elite and the rich in Chinese society have always enjoyed some degree of privacy in family life. As far as spatial privacy is concerned, the houses of elite and well-to-do families all drew a clear line between the exteriority of the community and the interiority of the home..." ${ }^{19}$ Chinese cities were built to encapsulate the

${ }^{17}$ Yan, Yunxiang, Making Room for Intimacy, House Home Family: Living and Being Chinese, ed. By Knapp, Ronald G. and Lo, Kai-Yin (2005) Spatial Habitus, p. 392.

18 Solove and Schwartz, Information Privacy Law, $5^{\text {th }}$ ed., quoting Lu Yao-Huai, Privacy and Data Privacy Issues in Contemporary China, 7 Ethics \& Ino. Tech. 15 (2005).

${ }^{19}$ Yan, Yunxiang, Making Room for Intimacy, House Home Family: Living and Being 
family unit in courtyard-style residences. ${ }^{20}$ The family's outdoor activities would be in this private space rather than the front or back yard of the home. The family would close the windows facing the street and the outside, keeping the courtyards "closed and secluded. ${ }^{21}$ This architectural phenomenon would serve the family-centered need for privacy.

Even the burial tomb of the Mausoleum of Emperor Qin Shi Huang is composed of "an inside square wall with perimeter of 1.6 miles and a surrounding outside enclosure with a perimeter of 3.9 miles." 22 Given vast resources, this powerful Emperor built himself a perpetual courtyard residence devoted to private space.

Generational changes with younger married couples wanting their own space has changed the reception of guests into the home. Now they are expected to meet in the living room and are not invited into the bedroom or private spaces. ${ }^{23}$ New houses are now built in China to accommodate increasing demands for privacy. "Where once several conjugal units shared one large sleeping space, houses are now generally built with separate rooms for each couple." ${ }^{24}$

\section{Saving Face by Protecting One's Status in the Community --- A privacy screen protects the individual from public shame.}

These historical and cultural considerations inform a distinctly Chinese view of privacy. In the Judeo-Christian Western culture, it's arguable that punishment is based on the personal and inward-facing ideas of individual wrongdoing and individual guilt. ${ }^{25}$ However, in Chinese culture,

Chinese, ed. By Knapp, Ronald G. and Lo, Kai-Yin (2005) Spatial Habitus, p. 390-391.

${ }^{20}$ This is historically true for the upper class and property rights and values were actually fairly similar to what you'd find in, say, feudal England. Large estates, importance of family ownership, were quite common. As is discussed supra, this structure was not as applicable to the "lower classes" in history and changed in the transition to modern-day China.

${ }^{21}$ Fayuan, Zhu, Qixing, Wu, Hanning, Xia, and Han, Gao, From Moon Cakes to Mao to Modern China: An Introduction to Chinese Civilization, (2015) by CN Times Books, Inc., p. 194.

${ }^{22}$ Fayuan, Zhu, Qixing, Wu, Hanning, Xia, and Han, Gao, From Moon Cakes to Mao to Modern China: An Introduction to Chinese Civilization, (2015) by CN Times Books, Inc., p. 198.

${ }^{23}$ Yan, Yunxiang, Making Room for Intimacy, House Home Family: Living and Being Chinese, ed. By Knapp, Ronald G. and Lo, Kai-Yin (2005) Spatial Habitus, p. 386-389.

${ }^{24}$ Jervis, Nancy, The Meaning of Jia, House Home Family: Living and Being Chinese, ed. By Knapp, Ronald G. and Lo, Kai-Yin (2005) Spatial Habitus, p. 225-226.

25 Beginning with the biblical reference to the Ten Commandments, notions of individual responsibility for behavior are ingrained in Western culture. Each commandment 
punishment often derives from community-infused concepts based on the Confucian ideas of shame and deference to the community hierarchy. This concern with public shame has shaped the regulation of privacy in Chinese society.

Individuals are conditioned to at all costs avoid actions such a disclosure of sensitive facts that would lead to a loss of face and cause them shame. Further, the concept of "saving face" extends beyond any single individual to that person's family reputation. ${ }^{26}$ As if keeping one's own reputation clean and clear was not enough of an effort, in traditional Chinese culture the individual's actions reflect upon their family name and standing in the community. "If the house is disgraced, one should not scatter gossip to the wind," 27 is an expression that connotes that the concept that a house, or an entire family, can be disgraced by one person associated with that family. The expression also conveys that this shame must be kept within the family house, not to be shared with the village or the outside community.

"The traditional Chinese word for "privacy" is "yin-si". "Yin-si" consists of two Chinese words, which are "yin" and "si". "Yin" means "hidden from view. Usually, this is a word [that] possesses [a] derogatory sense and means illegitimate sexual in Chinese. "Si" means "private" or "do not want to disclose in public. This word covers both "private" and "privacy." "Yin-si" has been defined as an individual's shameful secret that the individual does not want to tell others or be disclosed to the public." 28

As seen through the traditional meaning of yin-si reflecting the desire to avoid further lost of face or humiliation, parties to a dispute over privacy might just let it pass or seek a resolution outside of a public forum. "...for the sake of 'face' even if the invasion of their privacy was inevitable, they

begins with, "Thou..." implying that an individual reader must follow the instructions regardless of the behavior of others or the situation in the community. Similarly, legal codification of these principles locate blame on individual actions.

26 "The significance of 'face' in Chinese society is widely known by now, so much so that the term has entered the English-speaking world. In general, scholars distinguish two kinds of face: social face, based on one's achievements and dignity, and moral face, based on a person's feelings of shame. The former works as a type of prestige and is subject to the evaluation of others, while the latter functions as a moral self-constraint." Yan, Yunxiang, Making Room for Intimacy, House Home Family: Living and Being Chinese, ed. By Knapp, Ronald G. and Lo, Kai-Yin (2005) Spatial Habitus, p. 395, fn. 4.

${ }^{27}$ Fayuan, Zhu, Qixing, Wu, Hanning, Xia, and Han, Gao, From Moon Cakes to Mao to Modern China: An Introduction to Chinese Civilization, (2015) by CN Times Books, Inc., p. 58.

${ }^{28}$ Wang, Hao, Protecting Privacy in China, A Research on China's Privacy Standards and the Possibility of Establishing the Right to Privacy and the Information Privacy Protection Legislation in Modern China, Springer-Verlag Berlin Heidelberg, 2011, p.34. 
preferred to ignore the invasion rather than go to court." 29

This community-oriented idea of shame also has other practical privacy implications. Whereas in Western countries the disclosure of certain information such as financial data and age may cause particular consternation, the disclosure of such information may not be as problematic in Chinese culture where's one's financial standing can serve as a point of pride, one's seniority engenders respect, and disclosure of certain information is an accepted part of establishing externally one's place within the community hierarchy. On the other hand in Chinese culture, individuals are particularly sensitive to the disclosure of information that may bring unwanted scrutiny on the traditional familial unit and the community such as the disclosure of information about mental illnesses, sexual orientation, and adoption of family members.

Perhaps paradoxically on the other hand, as one Chinese commentator $\underline{\text { notes }},{ }^{30}$ in a shame-based culture, purported wrongdoers can only be properly punished if their faults are exposed to the community and the punished are forced by society to correct their behavior. This correction must be based on what society thinks is morally important to do rather than based any guilt that a wrongdoer internally harbors. Under this exposure to the criticism of the community, an individual's privacy rights are often disregarded. In other words, because of the heightened importance Chinese culture places on face and shame, invasions of privacy became a useful method for Chinese society to regulate individual behavior. In such an environment, privacy laws are more likely to be seen as unwanted shields used to protect morally repugnant behavior than useful societal mechanisms. This cultural artifact is likely to have contributed to the privacy-invasive phenomena of 'human-flesh' search engines $^{31}$ that commonly engulf online communities in mainland China. These searches are used to expose individuals convicted in the public court of wrongdoing, and subject them to humiliation, usually via social media. ${ }^{32}$

${ }^{29}$ Wang, Hao, Protecting Privacy in China, A Research on China's Privacy Standards and the Possibility of Establishing the Right to Privacy and the Information Privacy Protection Legislation in Modern China, Springer-Verlag Berlin Heidelberg, 2011, p.65.

30 Tian Weimin, Shame Culture and Privacy Protection, Zhongnan University of Economics and Law, 2010, retrieved from http://shlx.pkulaw.cn/fulltext_form.aspx?Db=qikan\&Gid=1510094600\&keyword=\&Encod ingName $=$ gb2312\&Search_Mode $=$.

31 'Human-flesh' search engines are campaigns by online users to search and expose the identity and personal details of other Chinese citizens of interest and subject them to public humiliation. See Tao, "Internet Mass Hunting: A Balanced Protection of Privacy and Free Speech," Jurisprudence, Guangdong Business School, 2008, retrieved from http://shlx.pkulaw.cn/fulltext_form.aspx?Db=qikan\&Gid=1510068708\&keyword=\&Encod ingName $=\&$ Search_Mode $=$.

${ }^{32}$ F. Y. Wang et al., "A Study of the Human Flesh Search Engine: Crowd-Powered 


\section{E. Privacy law and regulation in Chinese culture supports the individual's role in the community rather than protecting the individual against the community as in the West.}

If the entire foundation for privacy law in China presupposes that supporting the stability of the community should take precedence over the needs of any one individual, there will be some difficult conflicts between the laws of West and East. Thus, tensions between Western theories of privacy and the reality in the Chinese legal system can be particularly problematic for the implementation of privacy laws since both forces are based on strong, and sometimes conflicting, value systems. Companies charged with implementing both regimes within a single compliance framework will be stretched to their limits to do so.

The aforementioned mix of cultural factors has produced a unique Chinese view towards privacy - a view that is strict in certain respects ${ }^{33}$ but lax in others. Understanding these cultural and historical factors can offer clues to how Chinese privacy law may develop in the future. It is also helpful to keep these considerations in mind when creating privacy practices that deal with Chinese consumers or Chinese corporations.

In many recent privacy-related disputes in China, the legal system has often sided with protecting the rights, values, and morals of the community over protecting the privacy rights of the individual. ${ }^{34}$ In such cases, national interests prevail over personal interests, and the difficult balance of privacy and security has a heavy weight on the side of security and community. ${ }^{35}$ As

Expansion of Online Knowledge," in Computer, vol. 43, no. 8, pp. 45-53, Aug. 2010.

doi: 10.1109/MC.2010.216.

33 This is illustrated in a "classical case", one about a letter recipient making the letters public. The Higher Court ruled it violates the privacy right of the one who wrote the letter. See "One of the top ten civil cases of the People's Court in 2014: Qian Zhongshu's copyright and privacy dispute arising from the auction of manuscripts", available at http://www.pkulaw.cn/case/pfnl 1970324840818622.html.

${ }^{34}$ Zhang Lihong, Analysis of jurisprudence and legal culture - Privacy fate of China, East China University of Political Science and Law, available at http://www.cnki.com.cn/Article/CJFDTotal-SDFX201401002.htm.

${ }^{35}$ For example, in a case related to a Shanghai high school's publication of two students' romantic tryst that was caught on the school's cameras, the trial and appeals courts both found that the school's publication of such information did not violate the privacy interests of the affected students since the overriding interest of the school in its actions was to provide guidance to its underaged students, in line with a school's important traditional role in the community to help shape the morals and behavior young people. See Shanghai No. 2 Intermediate Court, Decision No. 2106 (2004). In another example of the prevalence of community considerations over an individual's privacy rights, a prominent newspaper had reported on the circumstances behind the suicide of a man whose daughter gained renowned 
Lang Ping, CASS China, China on Global Governance explained in a recent video presentation, the problem is not whether to have the government involved, but how to have the government involved. ${ }^{36}$

Furthermore, as a result of both cultural assumptions and legal decisions, shame-based Chinese citizens are very protective of their public image and any disclosure of private wrongdoing, whether legal or moral, that could lead to a loss of 'face.' Generally, individuals in the United States are given a wide berth until they violate the law. Then they "fall off the cliff" and are punished, whereas Chinese culture provides more support along the way, conforming behavior to social norms and preventing this fall. Hence the need for fewer lawyers, less law, fewer courts, less implementation. ${ }^{37}$ Saving face rather than airing grievances is the impetus behind the privacy and confidentiality laws that do exist in China today, and could point to the direction that Chinese privacy laws might further develop in the future.

\section{Current State of Privacy Laws in China}

Privacy law in China is still a relatively new field, and the definition of privacy in the legal context is still in its formative stages. To begin, a "working definition of privacy should also meet the following two criteria in China. First, individuals should understand all (or at least most) of the aspects of their personal information, which are being addressed. In other words, individuals should know when privacy is, or is not, gained or lost. Otherwise, the definition of privacy will be inaccurate. Second, the definition of privacy must be applicable to Chinese social and legal practices. Social and legal practices include the use and testing of the definition by Chinese courts, lawyers, and other governmental agencies. Particularly, a definition of privacy should be adequate for use in the legal process." 38

While this is properly the subject of another fascinating law review article, it is worth mentioning here that China is still working out whether corporations and other legal entities should have any privacy rights beyond

for chasing after a famous Hong Kong singer. The man's family sued for a violation of their privacy rights and on appeal, a Chinese court found that there was no violation of anyone's privacy rights because the newspaper had a public interest to the community to expose the harms caused by such star-chasing ways. See Guangzhou Intermediate Court, Decision No. 3871 (2008).

36 https://www.youtube.com/watch?v=lh-S3Bu9Qec\&app=desktop Raisina Dialogue 2016 | Securing Digital Asia: Threats and Opportunities for a Smart Realm.

${ }^{37}$ Law Without Lawyers: A Comprehensive View of Law in China and the United States, by Victor H. Li. 1978, p. 38-47.

${ }^{38}$ Wang, Hao, Protecting Privacy in China, A Research on China's Privacy Standards and the Possibility of Establishing the Right to Privacy and the Information Privacy Protection Legislation in Modern China, Springer-Verlag Berlin Heidelberg, 2011, pp.7-8. 
trade secrets and other intellectual property rights, i.e., “...similar to an individual [who] hopes to keep his or her personal information out of public view, an organization also need[s] internal privacy to conduct its affairs without having to keep up a 'public face.' That is to say enterprise legal persons also need the right to decide when and to what extent their information should be made public." 39

To understand the current state of Chinese privacy laws, it is best to first distinguish the concepts of privacy from government actors and privacy from corporate actors. China's current legal system does not afford significant privacy protections against government intrusion. ${ }^{40}$ Looking first at the basics of the Constitution of the People's Republic of China published in 1982, we can see that the text imposes privacy obligations on people and corporations, and protects basic citizens' rights and their personal dignity against private actions. It does not necessarily restrict government actions. ${ }^{41}$ According to Wang, "In fact, in the domain of Chinese jurisdiction, 'personal dignity' is a specialized phrase. "Personal dignity' can be understood as the right to name, right to portrait, right to privacy and so on." 42

While China still lacks a comprehensive national privacy law, privacy laws and regulatory guides focused on specific concerns have been passed. Chinese privacy law has a sectorial focus (laws governing specific industries or areas), similar to the U.S. sectorial approach to privacy. These sectors vary from telecommunications, Internet users, and consumer protection regulation as well as tort rights of action. Traditionally, like the Chinese Constitution, these laws have protected individuals against private corporations, but are not equivalent to a U.S. Bill of Rights protecting individuals against their own government's power.

In the past few years, China has been increasingly willing to create and enforce privacy laws aimed at regulating corporations and private actors. Furthermore while these new laws codified privacy protection, they still offered a worldview that superimposed the general Chinese cultural values

39 Wang, Hao, Protecting Privacy in China, A Research on China's Privacy Standards and the Possibility of Establishing the Right to Privacy and the Information Privacy Protection Legislation in Modern China, Springer-Verlag Berlin Heidelberg, 2011, p.47, quoted expression from Westin (1967) Privacy and Freedom, Atheneum New York.

40 See, e.g., detailed descriptions and lists of permitted and unpermitted activities and speech in the media Chinese Cultural Laws Regulations and Institutions, ed. by Gao Shuxun, 2009, at pp. 38, 105-106 and 111-112.

${ }^{41}$ Wang, Hao, Protecting Privacy in China, A Research on China's Privacy Standards and the Possibility of Establishing the Right to Privacy and the Information Privacy Protection Legislation in Modern China, Springer-Verlag Berlin Heidelberg, 2011, p.51.

${ }^{42}$ Wang, Hao, Protecting Privacy in China, A Research on China's Privacy Standards and the Possibility of Establishing the Right to Privacy and the Information Privacy Protection Legislation in Modern China, Springer-Verlag Berlin Heidelberg, 2011, p.52. 
of the community interests and morality into the privacy discussion.

\section{A. Consumer Protection Privacy Laws.}

One of the first of these new laws, in 2012, the SC-NPC Decision on Internet Information Protection ("SC-NPC 2012") ${ }^{43}$ created the highest level law in China dealing with data protection. The provisions from SC-NPC 2012 were largely included in the 2013 amendments to China's Law on the Protection of Consumer Rights and Interests ("Consumer Law"). ${ }^{44}$ The amended Consumer Law includes the general principle that all operators must "follow legal, legitimate, and necessary principles," incorporating principles stated in the SC-NPC 2012.

The Consumer Law, Art. 29 lists these rules that are widely accepted in the privacy space:

"Proprietors collecting and using consumers' personal information shall abide by principles of legality, propriety and necessity, explicitly stating the purposes, means and scope for collecting or using information, and obtaining the consumers' consent. Proprietors collecting or using consumers' personal information shall disclose their rules for their collection or use of this information, and must not collect or use information in violation of laws, regulations or agreements between the parties.

Proprietors and their employees must keep consumers' personal information they collect strictly confidential and must not disclose, sell, or illegally provide it to others. Proprietors shall employ technical measures and other necessary measures to ensure information security, and to prevent consumers' personal information from being disclosed or lost. In situations where information has been or might be disclosed or lost, proprietors shall immediately adopt remedial measures.

Proprietors must not send commercial information to consumers without their consent or upon their request of consumers, or where they have clearly refused it."

A more recent regulation from 2015, the Measures for Punishment of

${ }^{43}$ National People's Congress Standing Committee Decision concerning Strengthening Network Information Protection, December 29, 2012, edited by Rogier Creemers, Retrieved from https://chinacopyrightandmedia.wordpress.com/2012/12/28/national-peoplescongress-standing-committee-decision-concerning-strengthening-network-informationprotection/.

44 The Decision on Amending the PRC Law on the Protection of Consumer Rights and Interests was adopted at the 5th Session of the Standing Committee of the Twelfth National People's Congress on October 25, 2013, was released to take effect on March 15, 2014. Consumer Protection Law (Including 2013 Amendments), Retrieved from $\mathrm{http} / /$ chinalawtranslate.com/consumer-protection-law-including-2013amendments/?lang=en. 
Infringements of Consumer Rights and Interest by the State Administration for Industry and Commerce, is applicable to consumer personal information and contains similar prohibitions as the Consumer Law. Perhaps most importantly, this regulation defines consumer personal information, one of the first instances of this definition in Chinese regulations, as the following (Art. 11): "information collected by an enterprise operator during the sale of products or provision of services, that can, singly or in combination with other information, identify a consumer." Examples include "name, gender, occupation, birth date, identification card number, residential address, contact information, income and financial status, health status, and consumption habits."

\section{B. The Telecommunications Privacy Regulations}

Various recent telecommunications regulations on privacy include the 2011 Ministry of Industry and Information Technology ${ }^{45}$ Internet Information Services Regulations ("MIIT 2011 Regulation") 46 the 2013 MIIT Telecommunications and Internet Personal User Data Protection Regulations ("MIIT 2013 Regulation");" the 2013 MIIT Information Security Technology - Guidelines for Personal Information Within Public and Commercial Services Systems ("MIIT 2013 Guide"). ${ }^{48}$

The general principles of MIIT 2011 Regulation states that ISPs "shall provide services in accordance with the principles of equality, free will, fairness and good faith."

In the MIIT's 2013 Guide, the MIIT released a voluntary guide for industry best practices, elucidates eight principles, which are all fairly standard for international privacy norms ${ }^{49}$ and similar to other nations'

45 China's Ministry of Industry and Information Technology ("MIIT") is one of the country's main Internet and telecommunications regulators.

46 Specification of Internet information service market order and a number of provisions, by Minister Miao Wei, retrieved from http://www.miit.gov.cn/n1 1293472/n11293832/n12771663/14417081.html.

47 Telecommunications and Internet Personal User Data Protection Regulations, December 29, 2013, People's Republic of China, Ministry of Industry and Information Technology Decree, edited by Rogier Creemers, retrieved from https://chinacopyrightandmedia.wordpress.com/2013/07/16/telecommunications-andinternet-user-individual-information-protection-regulations/

48 Information Security Technology-Guideline for Personal Information Protection Within Information System for Public and Commercial Services, 2013, retrieved from http://www.pipa.gov.cn/manage/UploadFile/2015518133720563.pdf.

49 See generally Regulation on the protection of natural persons with regard to the processing of personal data and on the free movement of such data, and repealing Directive 95/46/EC (General Data Protection Regulation) (“GDPR”), available at http://eur- 
privacy principles: ${ }^{50}$

1. Clear Purpose Principle: Data should only be used for a clear purpose and should not be used outside of that purpose.

2. Minimum and Sufficiency Principle: Companies should only handle the minimum amount of information sufficient for their purpose. Personal information should be deleted after the purpose has been achieved.

3. Public Notification Principle: Companies should give notice to data subjects of the purpose, scope, use, security, and other information related to the data collection.

4. Personal Consent Principle: Companies should obtain consent before using data.

5. Quality Assurance Principle: Companies should take measures to ensure confidentiality, integrity, and availability of data.

6. Safety Guarantee Principle: Companies should take measures to ensure security of data.

7. Good Faith Fulfilling Principle: Companies should act in good faith in compliance with legal requirements.

8. Clear Responsibility Principle: Companies should clearly define responsibilities, take appropriate measures, and maintain records (for use in potential future investigations).$^{51}$

These principles should seem thematically familiar to any international privacy practitioner. ${ }^{52}$ Additionally, the MIIT 2013 Guide includes the following: special safeguards for sensitive information, restrictions for overseas data exports, data breach notification obligations, and information on rights of data subjects. The MIIT 2013 Guide is the only current international state's policy that mentions limits on transnational data exportation, explicitly prohibiting overseas transfer of data without express consent of data subjects or explicit legal or regulatory permission. However,

lex.europa.eu/legal-content/EN/TXT/HTML/?uri=CELEX:32016R0679\&from=en.

50 See generally Fair Information Practice Principles. National Strategy for Trusted Identities in Cyberspace. Appendix A. National Institute of Standards and Technology. http://www.nist.gov/nstic/NISTIC-FIPPs.pdf.

${ }^{51}$ Similar guidance requiring that online entities only collect, process, and use of user personal information only for legitimate and necessary purposes and with user consent can also be found in more recent laws and regulations such as the the Cybersecurity Law (National People's Congress) (2016), State Administration for Industry and Commerce Draft Implementation of the Law of the People's Republic of China on Protection of Consumer Rights and Interests (2016), and the Standing Committee of the National People's Congress of China's Draft of the E-commerce Law (2017).

52 The profession of privacy practitioner has developed with the aid of trade organizations such as the International Association of Privacy Professionals (IAPP) at https://iapp.org/about. Such organizations offer training and certifications. 
the MIIT 2013 Guide is voluntary and does not impose legal obligations upon corporations.

\section{Internet Access Privacy Regulations}

A government agency heavily involved in this space is the relatively recently formed Cybersecurity Administration of China (CAC), the main Chinese Internet content regulator.

In 2016, after several drafts, China's new Cybersecurity Law, a wide encompassing law governing online activities, was passed, effective June 1, 2017. The CAC was the main government body tasked with administering the law. Of interest to this paper, under the law, websites must require users to disclose their real life identity when registering for website services, a strengthening of prior laws in the same vein. ${ }^{53}$

The Cybersecurity Law also represents one of the first national legislation in China to establish legal principles for the protection of personal data online (as opposed to other past practices which were governed by administrative rules, judicial interpretations, government policies and nonbinding industry guidelines). Among other things, the law requires websites to protect their users' personal data and not share it with others, notify users of the purposes, means, and scope of their data collection, obtain user consent, and notify the authorities and users of any data breaches. Websites that violate these data protection laws may face fines up to ten times the amount of unlawful gains from the improper use of user data or a fine of up to $1,000,000 \mathrm{RMB}(\$ 140,500)$, have their employees face fines, and in serious cases, have their websites' operations be terminated.

In line with some of the cultural elements of Chinese privacy discussed previously, the law also asks all persons and organizations online "observe public order and respect social morality" and to "provide technical support and assistance to public security organs' and state security organs." ${ }^{, 54}$ Online service providers themselves are similarly asked to "to obey social morals

\footnotetext{
53 The Cybersecurity Law of the People's Republic of China (National People's Congress), November 7, 2016, retrieved from http://www.chinalawtranslate.com/cybersecuritylaw/?lang=en. An earlier regulation covering this issue was CAC's Administrative Regulation on Internet Users' Account Names (2015). The regulation also required online users to register accounts on websites with their real name, through provision of identification materials. One commentator noted that the real name registration requirements "came after a series of corruption scandals among lowerlevel officials exposed by internet users," and seems to apply not only to individuals but also to service providers. See Scaife, Laura, Handbook of Social Media and the Law, InformaLaw from Routledge, (2015), pp. 117-118.

${ }^{54}$ The Cybersecurity Law, Articles 12 and 28.
} 
and commercial ethics. ${ }^{" 55}$ Nevertheless, like with most other privacy-related regulations in China, these protections under the Cybersecurity Law do not appear to extend to governmental actions.

In 2016, the CAC also published the Draft Administrative Rules on Internet News Information Service, which imposes a number of legal requirements on "internet news information services" (Internet news content providers). Of relevance to privacy, these requirements include the following:

- Internet content providers can collect users' personal identity information if the providers have already published their collection rules and record retention policies.

- User information, other than identity information, may be collected only with consent from users.

- Internet news providers will be required to retain within China for at least 60 days a record of the Internet news published or reposted by themselves or any users. Such information must be provided to government agencies upon their request.

- Internet news providers and users may not copy, publish or distribute the identifiable information or privacy information of others, unless otherwise provided by laws or agreed by the relevant persons.

These new regulations, like most new Chinese privacy laws, serve to protect individuals' personal information. At the same time, in allowing the Chinese government to better track online user's personal information, they highlight government exemptions inherent in Chinese theories of privacy protection.

The unique name regulation also enforces a form of transparency in user account names. Analyzing this new development through the lens of saving face, we can view this regulation as a form of protection of the community enforcing honesty in online community relationships. This regulation arguably does not invade privacy interests because personal information is still protected from unwanted disclosure. Thus, though this regulation may at first seem at odds with the other privacy-centric, community-focused Chinese privacy laws, this is actually a particularly cogent example of Chinese legislation perhaps being formed with the influence of Chinese cultural history.

\section{Criminal and Civil Law Privacy Protections}

Chinese citizens also have privacy protection under Chinese Civil and Criminal Laws.

${ }^{55}$ The Cybersecurity Law, Articles 9. 
Chinese citizens can protect their privacy rights under the country's tort law. China's General Principles of Civil Law ("GPCL") ${ }^{56}$ includes protection of the "right of personal name" (GPCL, art. 99), "right of portrait" (GPCL, art. 100), "right of reputation" (GPCL, art. 101), ${ }^{57}$ while the Tort Liability Law ("TTL") ${ }^{58}$ protects the "right of privacy" (TTL, art. 2) ${ }^{59}$ Both the GPCL and TTL tort rights of privacy have been used in litigation between individuals and corporations. It is important to note that, under the TTL, "network service providers" (likely to be interpreted as similar to "Internet Service Providers" in the West) have special obligations to prevent tortious actions committed by users of their services.

Three opinions interpreted the GPCL law shortly after enactment:

(a) Chinese People's Supreme Court, Opinions on Several Questions concerning the Implementation of the GPCL (1988), held that "If anyone propagates the privacy of any other person in writing or orally, or fakes acts to vilify the personality of other person overtly, or damages other person's reputation by ways of insulting and slandering, which result in a certain influence, such act shall be determined as an act infringing the citizen's right of reputation." 60

(b) A literary work can damage a person's reputation by "insulting, libeling, or disclosing the privacy of the certain person...in spite of not identifying the real name or address..." ${ }^{\prime 61}$; and

(c) Infringing on another person's "privacy or other personality interests...taking tort as the cause to get compensation for spiritual damages,"

${ }^{56}$ General Principles of the Civil Law of the People's Republic of China, available at http://www.npc.gov.cn/englishnpc/Law/2007-12/12/content_1383941.htm

${ }^{57}$ Under Article 99, citizens enjoy the right to use their personal names as they desire. Under Article 100, the use of a citizen's protrain without their consent is prohibited. Under Article 101, citizens and legal persons shall enjoy the right of reputation. The personality of citizens shall be protected by law, and the use of insults, libel or other means to damage the reputation of citizens or legal persons shall be prohibited.

58 Tort Liability Law, http://www.npc.gov.cn/englishnpc/Law/200712/12/content 1383941.htm.

${ }^{59}$ Article 2 notes "Those who infringe upon civil rights and interests shall be subject to the tort liability according to this Law. Civil rights and interests used in this Law shall include the right to life, the right to health, the right to name, the right to reputation, the right to honor, right to self image, right of privacy, marital autonomy, guardianship, ownership, usufruct, security interest, copyright, patent right, exclusive right to use a trademark, right to discovery, equities, right of succession, and other personal and property rights and interests."

${ }^{60}$ Chinese People's Supreme Court, Opinions of the Supreme People's Court on Several Issues concerning the General Principles of the Civil Law of the People's Republic of China (for Trial Implementation) answer 140(1).

${ }^{61}$ Reply to Several Questions on Adjudicating the Cases of the Rights of Reputation (1993) answer 7. 
will also be actionable. ${ }^{62}$

In terms of applications of these laws, cases, like those elsewhere, often turn on the facts, but in China the courts are quite explicit about the moral underpinnings of the decisions. For example, a court noted in a divorce case that "People involved in bigamy or cohabits [cohabitation] with a married person can claim their right to privacy to defend any third party, but they cannot use right to privacy as the excuse of their immoral act or to prohibit their spouse's right to know. ${ }^{63}$

However, in a more recent case from 2008, we saw a transition from the traditional notions of privacy. In the case, Wang Fei v. Zhang Leyi, Daqi.com, and Tianya.cn, the Plaintiff Wang Fei sued Zhang Leyi, a friend of his wife who had committed suicide supposedly due to Wang's infidelity, and two web portals for Zhang's posting on those platforms information about Wang's actions, his address, and other personal details. ${ }^{64}$ Thus, the Wang Fei case went to the heart of what most societies see as the core privacy values, including identifying an individual and spreading information about their most personal history. The definition of privacy the court found in this case is relatively close to a Western ideal of privacy, a concept of privacy that meant private life, information, space, and peace of private life related to a person's interests and personality that he does not intend to share with others. Based on this, and despite Wang's supposedly immoral acts, the court found the right to privacy is infringed by the disclosure or publication of private information that a person does not want to disclose to others concerning his private life, private areas, or domestic tranquility and connected with his interests or his body. ${ }^{65}$

Subsequently, a new version of the Tort law in China was promulgated in 2009, which referred at least obliquely to the right of privacy. The Tort Law is a broad sweep of a document, including twelve chapters and ninetytwo provisions, and it delves into tort principles and lays out the parameters of tort liability. Specifically, "Article 2 of the Tort Law provides that tortious liability arises when there is an infringement of 'civil rights and interests' a

${ }^{62}$ Interpretation of the Supreme People's Court Regarding issues of Ascertaining the Liability of Compensation for Spiritual Damage for Tort (2001) art. 1.

63 Wang, Hao, Protecting Privacy in China, A Research on China's Privacy Standards and the Possibility of Establishing the Right to Privacy and the Information Privacy Protection Legislation in Modern China, Springer-Verlag Berlin Heidelberg, 2011, p.49, quoting Jia M(2006) Red book of Divorce (Wang Hao trans) http://www.iamlawyer/redbook/redbook.doc, p.48 discussion of Luo Ling v. Wu case.

${ }^{64}$ Wang Fei $v$ Zhang Leyi, Daqi.com and Tianya.cn, Beijing Chaoyang District Court, No. 10930 of 2008 .

${ }^{65}$ Wang Fei v Zhang Leyi, Daqi.com and Tianya.cn, Beijing Chaoyang District Court, No. 10930 of 2008 . 
broad term that refers to personal and property rights, including the right to life, the right to health, rights associated with names, reputation rights, the right of honor, and the right to one's image. Also included in Article 2 are the rights to privacy." 66

The most recent guidance on tort liability for privacy can be found in the Supreme Court's publication of Provisions on Several Issues Concerning the Application of Law to Adjudicate Civil Disputes Involving Infringement of Personal Rights Via Information Networks from 2014. The provisions direct courts to support tort claims associated with disclosure by network users and network service providers of private information and other personal information, such as genetic information, medical records, health examination materials, criminal records, home addresses and information regarding private activities. Under these provisions, the following are not basis for tort claims for disclosure of personal information (emphasis added to indicate the exemption again for the amorphous idea of "public interest"):

$\circ \quad$ disclosure with the written consent of the relevant individual and within the agreed scope;

$\circ \quad$ disclosure for the public interest to the extent necessary; and

- disclosure by an educational or scientific entity for public interest in connection with academic research or statistical analysis, provided that the relevant individual information has been sufficiently de-anonymized and the subjects have given written consent.

The provision also includes a couple of additional "safe harbors" for disclosure of personal information: 1) disclosure where the relevant personal information has already been publicly disclosed by the relevant individual himself or herself online; or 2) has already become public via other lawful means. However, in the last two situations, network users and network service providers may still be liable if the method of disclosure "violates the public interest or social morals" or if the disclosure harms a material interest of the individual whose personal information is publicly disclosed.

The Ninth Amendments to the PRC Criminal Law (2015) revised the former prohibition on selling personal information to a broader prohibition (Art. 253): Anyone who sells or provides personal information, in violation

\footnotetext{
${ }^{66}$ The Legal System of the People's Republic of China, by Daniel C.K. Chou. 3rd ed. (2015), pp. 363-364.
} 
of national provisions, to third parties is subject to punishment. ${ }^{6768}$ There are also now increased punishments for such violations. Additionally, this law now includes a new provision (Art. 286): network service providers (both ISPs and content providers) are subject to criminal fines and punishment for leaks of user information that leads to serious consequences.

An individual action to invade another person's privacy may not be permissible but a corporate action to invade a person's privacy might well be permissible. In Zhang Desheng, Zhong Guifang, and Zhang Zhong v. Yang Hongyan, Lu Ying and Yang Jun, (Shanghai 2nd Intermediate People's Court, Order Number 335 (2014)), the intermediate court upheld a decision finding a right to privacy violation where an upstairs neighbour had installed a camera monitoring the entrance to the downstairs neighbour's apartment. On the other hand, in Yang v. a Property Management Company, (Shanghai 1st Intermediate People's Court, Order Number 798 (2013), the court dismissed a complaint alleging a "right to privacy" violation where a building's management had installed a camera monitoring a common area that included views of the plaintiff's doorway." ${ }^{69}$ Individuals can now request information about other individuals from their online service providers in China. "Article 4 [of the China's Supreme People's Court (SPC)'s SPC Regulation on 23 June, 2014] was therefore added to ensure that online tortfeasors could not take refuge behind a mask of Internet anonymity to violate the rights of others... To our knowledge, this is the first provision in Chinese law that permits a private citizen to request another's private information from a

${ }^{67}$ Note, not mentioned in this article, but in 2013, the Supreme People's Court, Supreme People's Procuratorate, and Ministry of Public Security jointly issued Gong Tong Zi [2013], No. 12 (Criminal Data Privacy Notice), which defined personal information to include "'information and data that could identify a citizens' personal identity or were related to the privacy of a citizen, such as their name, age, identification number, marital status, work unit, education background, curriculum vitae, home address, and telephone number."

${ }^{68}$ Note, a prominent prosecution under the previous variant of Article 253 is the case of Peter Humphrey, a private investigator hired by the drug giant GlaxoSmithKline (GSK) to investigate charges of bribery in its Chinese operations by Chinese authorities. During the investigation, Mr. Humphrey collected information on relevant individuals to the case. Mr. Humphrey and his wife were later arrested and imprisoned for his illegal collection and sale of personal information under Article 253. Although one can see this case as the increase scrutiny paid by authorities to Chinese privacy regulations, the case can also be interpreted as an example of power of the State to selectively enforce laws against actors seen to be detrimental to itself.

${ }^{69}$ Scott and Greenleaf, Graham, The Emergence of Tort Liability for Online Privacy Violations in China (June 1, 2015). (2015) 135 Privacy Laws \& Business International Report 22-24; UNSW Law Research Paper No. 2015-54. Available at SSRN: http://ssrn.com/abstract=2636129 p. 22-24, footnotes 21-22. 
network service provider. ${ }^{70}$

What's the consequence of this suggested liability? Search engines and other online service providers may need to consider the development of a similar right to be forgotten in China. "it is worth noting that Article 5 of the SPC Regulation has the potential to allow a Chinese equivalent of the European Union's so-called 'right to be forgotten' to develop, if it is used in relation to TLL Article 2. This bears watching over time." 71

When you have a new statute allowing civil liability, you presumably generate more case law, as "[o]ther than in the Philippines, no other common law jurisdiction has created such statutory rights, or developed a tort of invasion of privacy (or its approximation via extending the law of breach of confidence). With the additional clarifications offered by the SPC Regulation, we can expect to see a rise in privacy-related civil actions in China that should provide important future guidance for defining the contours of China's "right to privacy" in the online era." 72

Even so, Chinese privacy law has not changed as rapidly as one might have expected. There have been a number of new laws, but no (or few) new cases. There are some theories positing why the cases have arisen slowly in the privacy context. "According to legal scholars, one reason for the discrepancy may be that Chinese practitioners and courts have lacked understanding on how to apply Article 36 (the provision permitting civil suits against network service providers or network users for online infringement of personal rights) in practice, with the result that few actions have been initiated by practitioners or accepted by courts since the passage of the TLL in 2009." 73

${ }^{70}$ Livingston, Scott and Greenleaf, Graham, Tort Liability for Online Privacy Violations in China: The 2014 SPC Regulation (July 1, 2015). (2015) 136 Privacy Laws \& Business International Report, 24-27; UNSW Law Research Paper No. 2015-65. Available at SSRN: http://ssrn.com/abstract $=2677533$

${ }^{71}$ Livingston, Scott and Greenleaf, Graham, Tort Liability for Online Privacy Violations in China: The 2014 SPC Regulation (July 1, 2015). (2015) 136 Privacy Laws \& Business International Report, 24-27; UNSW Law Research Paper No. 2015-65. Available at SSRN: http://ssrn.com/abstract=2677533. In 2016, the passage of the new Cybersecurity law also introduced a similar "right to be forgotten" provision aimed at network providers, requiring them to delete a user's personal information on their request. See The Cybersecurity Law, Article 43 (National People's Congress) (2016)

${ }^{72}$ Livingston, Scott and Greenleaf, Graham, The Emergence of Tort Liability for Online Privacy Violations in China (June 1, 2015). (2015) 135 Privacy Laws \& Business International Report 22-24; UNSW Law Research Paper No. 2015-54. Available at SSRN: http://ssrn.com/abstract=2636129 p. 22-24.

${ }^{73}$ Livingston, Scott and Greenleaf, Graham, The Emergence of Tort Liability for Online Privacy Violations in China (June 1, 2015). (2015) 135 Privacy Laws \& Business International Report 22-24; UNSW Law Research Paper No. 2015-54. Available at SSRN: http://ssrn.com/abstract=2636129 p. 22-24, citing Rogier Creemers, Parsing the New 


\section{E. Chinese Legislation and Regulations on Privacy, Going Forward}

The aforementioned regulations and laws represent the main slate promulgated in recent years. China's other sectoral laws include the Basic Norms for Electronic Medical Records (Ministry of Health, 2010), ${ }^{74}$ Social Insurance Law (2010), ${ }^{75}$ Regulations and Administrative Measures for Credit Reference Agencies (2013). ${ }^{76}$ There are also securities regulations that provide assurances of correct information, and allow individuals to correct errors, meeting some of the fundamental conditions for the establishment of protecting personal information. Insurance regulations requiring confidential information be kept secure may also help protect personal privacy. ${ }^{77}$ In medical regulation, there is the Law on Practicing Doctors of the PRC (1988) that requires doctors to keep patient confidences. Law on Practicing Doctors of the PRC (1988), art. 37 (10). Finally, a number of provinces and municipalities have enacted their own privacy laws.

In addition to increasing privacy legislation, one critical trend to watch is China's increase in data localization requirements - a trend, which could indicate, increased willingness by the government to regulate the privacy activities of foreign businesses and the data of Chinese citizens. A number of recent laws, in drafts and implementation in China have included data localization requirements. ${ }^{78}$ Although these are most likely efforts to provide

Internet Rules of China's Supreme Court, China Copyright and Media, October 11, 2014, retrieved from https:/chinacopyrightandmedia.wordpress.com/2014/10/11/3701/. See also the statutory rights found in Japan, South Korea, Macau SAR, Taiwan and Vietnam: see 'Civil Code or tort actions', in Graham Greenleaf Asian Data Privacy Laws: Trade and Human Rights Perspectives (OUP, 2014), p474, with details in the respective chapters on each country.

${ }^{74}$ Basic Norms for Electronic Medical Records (Ministry of Health, 2010), available at http://www.lawinfochina.com/display.aspx?lib=law\&id=8006\&CGid=

75 Social Insurance (2010), available at http://www.mohrss.gov.cn/gjhzs/GJHZzhengcewenjian/201506/t20150625_212401.htm.

76 Asian Data Privacy Laws: Trade \& Human Rights Perspectives, p. 224, footnote 184.

${ }^{77}$ Wang, Hao, Protecting Privacy in China, A Research on China's Privacy Standards and the Possibility of Establishing the Right to Privacy and the Information Privacy Protection Legislation in Modern China, Springer-Verlag Berlin Heidelberg, 2011, p.55-56.

78 See, e.g., The Cybersecurity Law (National People's Congress) (2016) (requiring personal information of and important data collected and generated by an operator of critical information infrastructure to be stored in China); Draft Counterterrorism Law (National People's Congress) (2014) (requiring all Chinese websites and ISPs to hold data related to Chinese business in China; this data localization requirement was later removed due to protests in the 2016 promulgated version); Administrative Measures on Management of Population Health Information, Trial Rules (National Health and Family Planning Commission) (2014) (requiring health institutions must store all medical information in 
the Chinese government with greater control of the Internet in China, these requirements also affect how much private data is subject to Chinese laws. It remains to be seen whether China will adopt an omnibus data localization law, perhaps similar to Russia's 2015 Data Localization Law. ${ }^{79}$

With all of these burgeoning regulations, perhaps the most pertinent question for foreign entities may now be: Do we even want to do business in China given these additional burdens? "As China's network service providers are already tasked with scanning their networks for content harmful to the State, the addition of a requirement to monitor content potentially infringing another's civil rights is likely to further increase their operational costs and burden." ${ }^{80}$ Civil suit remedies seem minor by U.S. litigation and especially by U.S. class action standards, but may have some impact. "Articles 16-18 [of the SPC] deal with the remedies available against both network users and network service providers. They included requirements to make apologies and restore reputation, with the Court able to publish its own 'online declaration' concerning a matter, or publish court documents, if this becomes necessary (Art. 16). Where infringements result in "asset losses or grave spiritual harm", compensation may be required (Art. 17), and may include reasonable expenses and lawyer's fees of victims (Art. 18). Where it is not possible to assess asset losses or an account of profits, the Court may make its assessment up to 500,000 yuan (US\$80,000)." 81

While Chinese privacy law is still fairly undeveloped, China has made significant strides in recent years to create new laws governing data privacy and confidentiality of personal information. As outlined, some of the major

China).

${ }^{79}$ Russia's Data Localization Law, which went into effect September 2015, instituted a number of requirements for foreign companies processing data of Russian citizens. Many of these requirements were seen as invasive or difficult to comply with, according to statements by technology companies. The most important requirement in the Russian Data Localization Law was a requirement that foreign companies processing data of Russian citizens physically process such data within Russia. This effectively required foreign companies to either create physical offices in Russia or to hire a Russian data processing company as an intermediary. The law has not yet been enforced against any major foreign companies. However, if China were to follow Russia's example and incorporate more data localization requirements, this could create numerous new privacy concerns for international businesses seeking to tap the Chinese market.

${ }^{80}$ Livingston, Scott and Greenleaf, Graham, Tort Liability for Online Privacy Violations in China: The 2014 SPC Regulation (July 1, 2015). (2015) 136 Privacy Laws \& Business International Report, 24-27; UNSW Law Research Paper No. 2015-65. Available at SSRN: http://ssrn.com/abstract=2677533.

${ }^{81}$ Livingston, Scott and Greenleaf, Graham, Tort Liability for Online Privacy Violations in China: The 2014 SPC Regulation (July 1, 2015). (2015) 136 Privacy Laws \& Business International Report, 24-27; UNSW Law Research Paper No. 2015-65. Available at SSRN: http://ssrn.com/abstract $=2677533$ 
principles inherent in the highest level Chinese privacy laws are similar to international privacy norms (E.U. Directive, APEC Principles, etc.). Nevertheless, their implementation and application must be seen in the Chinese cultural context.

With the various legal regimes are still unclear, the best way forward for privacy practitioners is to ensure compliance with current laws and proactively adapt practices that are in touch with Chinese consumer culture and its acceptance of community and governmental interest in private affairs.

\section{PRACTICAL LESSONS}

It is difficult to predict with great certainty how privacy law in China will develop. Chinese privacy laws are still in their early stages of implementation. There is no comprehensive national privacy law, and the regulations and governmental guidance that exist contain elements nominally similar to international norms (e.g. notice, choice, security, etc.) in many respects even if they include, as applied, various Chinese characteristics (e.g. exemptions for the government and the public interest). As described above, examining the unique historical and cultural factors will provide some clues to how privacy law will develop and be applied in China.

Looking at the collective, even in $21^{\text {st }}$ century China, will have some positive benefits, "...if privacy encourages public participation in political decisions by enabling citizens to form judgments and express preferences on social issues, establishing adequate privacy protection will provide a harmonious environment for China to achieve greater democracy pursuant to the Chinese Constitution." 82

Balancing is the key factor in creating a structure to support privacy rights in China going forward, as well as the participation and consideration of several stakeholders. When considering privacy in the balance, certain values emerge. Who is more important, collective or individual? Shall we consider an elite or upper class rule or society as a whole? To create this balance, it is "wrong to put privacy against other public interests. Privacy involves establishing a balance between individual and public...Therefore, when China defines different privacy interests, it is important to bear in mind that privacy interests will inevitably compete, collide, and coexist with other existing values in China, such as freedom of expression, freedom of the press, law enforcement, protection of the revenue, and the effective operation of

82 Wang, Hao, Protecting Privacy in China, A Research on China's Privacy Standards and the Possibility of Establishing the Right to Privacy and the Information Privacy Protection Legislation in Modern China, Springer-Verlag Berlin Heidelberg, 2011, pp.9-10. 
government. Privacy is significant, but it is not everything. Absolute privacy would mean a total withdrawal of an individual from our society. This will be undesirable for most Chinese people." 83

Privacy might have been considered in China as a way for the upper classes to keep themselves separate and to keep the lower classes out. In modern China, however, privacy has changed to allow individuals to control the flow of information about themselves on the internet- a more democratic, populist value. ${ }^{84}$ Further, there are gender and generational issues to consider. As women and children become more financially independent (move to the cities, into data rather than farm-based economies) they will demand more privacy as part of their individuality. ${ }^{85}$

Following is a list of practical suggestions to help privacy practitioners proactively protect their companies and their clients from legal privacy risks in China.

\section{A. Designing the Best China-Centric Privacy Policies}

1. Focus on community values

Given the Chinese emphasis on community values, it is advisable to design privacy policies and practices in context of an understanding of Chinese community values. For example, in framing a discussion of privacy policies, include a discussion of the values of the company's particular online community and explain how the draft privacy practices protect those values.

\section{Look to ethics, not just law}

Look to ethics first, not just the law. China does not yet have strong privacy laws, so the best basis for any privacy-related policy is to couch the program in ethical precepts. ${ }^{86}$ Chinese consumers may also be particularly swayed by ethical arguments for privacy practices, given historical focus on

${ }^{83}$ Wang, Hao, Protecting Privacy in China, A Research on China's Privacy Standards and the Possibility of Establishing the Right to Privacy and the Information Privacy Protection Legislation in Modern China, Springer-Verlag Berlin Heidelberg, 2011, p.7.

${ }^{84}$ Wang, Hao, Protecting Privacy in China, A Research on China's Privacy Standards and the Possibility of Establishing the Right to Privacy and the Information Privacy Protection Legislation in Modern China, Springer-Verlag Berlin Heidelberg, 2011, p.68.

${ }^{85}$ Wang, Hao, Protecting Privacy in China, A Research on China's Privacy Standards and the Possibility of Establishing the Right to Privacy and the Information Privacy Protection Legislation in Modern China, Springer-Verlag Berlin Heidelberg, 2011, p.71.

${ }^{86}$ As discussed earlier, Article 9 of new the Cybersecurity Law even asks online service providers to "obey social mores and commercial ethics." 
ethical bases for laws. To put this in practice, include an ethical basis when justifying the proposed privacy policies, in addition to providing the legal basis for the policies.

\section{Use culture for context}

In each country or region, it is wise to expect that different cultural values of privacy affect what the company's users want from corporations. In the U.S., users may view privacy almost as a property right (protecting private information a user owns). In China, users may instead view privacy as a shield, protecting their private lives from community exposure or the shame that comes from losing face. Recognize this distinction in privacy policies by emphasizing how the company will protect the confidences of customers, employees, and users and prevent information exposure.

\section{B. Understanding Chinese consumer expectations}

1. Chinese consumers may have fewer privacy expectations

Chinese consumers may place less value on privacy, when compared to other competing values or obligations. This may be reflected in what a company's user community and consumers value. For example, the company's users may care more or be affected more by corporate transparency efforts than privacy protection efforts. Thus, shareholders may receive a better return on investment for putting resources into creating and publishing transparency reports rather than spending resources on creating additional protections for personal data.

\section{Chinese consumers do care about privacy}

At the same time, privacy practitioners should not assume that Chinese consumers do not care at all about privacy. Cultural expectations of privacy may be different, but privacy is still valued in China, especially privacy concerning confidentiality of personal information. Keep in mind the notions of "shame" and "saving face," and the impact on the individual of the release of confidential information that may shame them in front of their community. It is important to remember that, while Chinese consumers may have a different conception of privacy rights, this is no excuse for not protecting the privacy of your consumers or failing to follow the law. Minimal data protection protocols are a worthwhile investment on an international, crosscultural basis. 
3. Chinese consumers may be more open to data collection/use

Chinese consumers may be more pragmatic about companies using or buying their private information. If the data collector can make a strong case for why users should give their data (e.g., in exchange for tailored features), it is likely that Chinese consumers will be more swayed by these arguments than European consumers, for many of whom privacy is an almost inalienable right. Privacy, in the European sense of the concept, is not a fundamental Chinese value, so Chinese consumers may be less constrained by adherence to pre-existing notions of strict privacy rights, when compared to Western consumers.

Understanding the cultural and historical factors behind China's privacy laws today provides a path forward in creating policies and programs that will best engage Chinese consumers and likely minimize future legal compliance risks. These practical privacy lessons can be used when conducting due diligence on new Chinese business interests, creating new policies for overseas corporate expansion, or interacting with Chinese user communities. Corporations wary of changing privacy laws can follow the model of technology companies working together to influence upcoming legislation, though it is uncertain if this model is as effective in China as it can be in the U.S. Another alternative could be to gather together in an industry forum to set standards for privacy. This solution not only resolves inter-company conflicts, but also may function like an insurance pool to reduce risks. ${ }^{87}$

As noted, Chinese privacy law is still fairly underdeveloped, and it is difficult to predict how the laws will change in the future. However, understanding the current state of Chinese privacy law, as well as the cultural and historical factors that might influence its development and application, will help organizations to succeed in the growing Chinese market.

\section{POLICY RECOMMENDATIONS}

\section{A. China - National and International Policy}

On a national scale, China has a fair distance to go before privacy laws become a cohesive body of law. As we've seen, the lack of strong privacy laws has made it difficult for some persons and companies to litigate, which may give rise to some unfair results if not remedied. Specifically, we recommend strengthening provisions protecting personal information so that

${ }^{87}$ Tim Hume, "Chinese Web Giants Join Forces in Crackdown on Online Rumors," CNN, August 2, 2013 , available at: http://www.cnn.com/2013/08/02/world/asia/chinaonline-rumor-crackdown/. 
corporations are held to a consistent standard that is understandable by consumers.

On an international scale, there is great potential for China to set the next generation's standards for privacy. With China's market power and increasing relevance in geopolitical discussions of technology, China's influence cannot be underestimated. Currently, the E.U. is by far the world's leader in pushing privacy norms for the international community. This is mostly achieved through the use of long arm jurisdiction, as recent EU privacy laws have succeeded in regulating even foreign companies with very weak ties to the E.U. Other countries, notably Russia with its latest Data Localization Law, have also attempted to regulate foreign corporations through similarly weak ties. The efficacy of these efforts has generally depended on the economic and political power of the nations proposing said regulation.

China, then, has the choice of approaching privacy law in an aggressive manner, similar to that of the EU, in order to enforce actions from foreign corporations, which would likely sway the legislation of other nations. Given the importance of privacy laws for information technology companies, extraterritorial jurisdiction for Chinese privacy laws could create key advantages for China in international negotiations.

Alternatively, China could choose to specifically refrain from pursuing stricter privacy laws, as but do so in a manner that contradicts EU privacy laws. This could lead to intriguing trade results as corporations choose to do business (and choose to lobby their governments) based on nation's laws. Simply put, China can use privacy laws to cement its place as a global leader, not only in privacy, but also technology as a whole.

One overlooked piece in this international privacy puzzle may be the future role of APEC in determining privacy standards. Currently, the United States is very active in APEC privacy discussions. However, this could change, if China were to choose to put more pressure on its neighbors in this realm. A united pan-Asian bloc could definitely create some interesting international privacy norms, and the clearest choice for leading that kind of endeavor would be China.

\section{B. Foreign Companies}

There are two ways to view the impact of a stronger Chinese privacy law system on the U.S. and the Western world at large. First, one could argue that a complicated, piecemeal system (as we have now in China) is confusing and easily manipulated by Chinese regulators against foreign companies. If so, it would make sense for foreign companies to lobby the Chinese government or their own governments to put pressure on China to clarify 
these laws.

However, it is more likely that a loosely connected body of privacy law acts in the favor of foreign companies. More regulations or more enforcement of regulations would necessarily create greater requirements for foreign corporations to comply with Chinese privacy laws. Thus, it is probably more advantageous for technology companies to not advocate for stronger laws or a more unified national body of privacy law.

\section{Foreign Governments}

Foreign governments may have incentive to attempt to influence the direction of Chinese privacy laws, both to protect their own technology industries as well as their own influence on international privacy norms. For example, if China were to strengthen privacy laws, in a manner more similar to EU privacy regulations, then the U.S. could be seen as falling behind on privacy rights. If China were to attempt increased extraterritorial jurisdiction over foreign companies dealing with Chinese consumers, then this would clearly affect international geopolitical considerations. Finally, international collaboration with China on the direction of privacy norms could be advantageous or disadvantageous for different nations, depending on goals.

\section{CONCLUSION}

In this paper, we've discussed the current state of Chinese privacy laws, in light of a selection of cultural factors that may have influenced and may continue to influence the future direction of such laws. With this understanding, we then offered recommendations for privacy practitioners and technology companies in general. Finally, we looked at some policy options for China, foreign companies, and foreign nations, giving the various interests of each particular type of party.

As mentioned, it is impossible to perfectly predict how China's privacy laws will develop. It is also impossible to completely accurately pinpoint how Chinese cultural values have directly influenced current laws. However, it is the Authors' hope that this Article will advance scholarly discussions around Chinese privacy laws, as well as the study of privacy and law, in general, in context of cultural considerations. After all, all nations are a product of unique cultural factors, and studying cultural factors is imperative for the true understanding of any legal system. In other words, while this Article specifically attempted to unmask the true face of Chinese privacy law, there are still many questions left to answer - not only about Chinese laws, but about laws in general, and about our national and international values of privacy. 
*** 